\title{
Public Preferences for a COVID-19 Vaccination Program in Quebec: A Discrete Choice Experiment
}

\author{
Gabin F. Morillon ${ }^{1,2,3} \cdot$ Thomas G. Poder ${ }^{1,2,3}$ (D) \\ Accepted: 29 November 2021 / Published online: 20 January 2022 \\ (c) The Author(s) 2022, corrected publication 2022
}

\begin{abstract}
Objectives We aimed to elicit preferences of the French-speaking Quebec population regarding a COVID-19 vaccination program and to characterize individuals with respect to their vaccination behaviors.

Methods A discrete choice experiment was conducted in Autumn 2020 via a web-based survey. Its design included seven attributes: vaccine origin, vaccine effectiveness, side effects, protection duration, priority population, waiting time to get vaccinated, and recommender of the vaccine. Utilities were estimated using a mixed-logit model and a latent class logit model. Results Our sample included 1599 individuals. From this total, 119 always chose the opt-out option (7.4\%). According to the mixed-logit model, the relative weights of attributes were as follows: effectiveness (28.48\%), side effects $(23.68 \%)$, protection duration $(17.41 \%)$, vaccine origin $(12.75 \%)$, recommender $(11.96 \%)$, waiting time to get vaccinated $(3.62 \%)$, and priority population $(2.11 \%)$. Five classes were derived from the latent class logit model. Class $1(9.13 \%)$ wanted to get vaccinated as fast as possible and was composed of uncertain and more vulnerable individuals. Class $5(25.14 \%)$ was similar to the full sample, mostly favoring vaccination. Classes 2 (7.69\%) and 4 (15.82\%) included "vaccine hesitant and demanding" individuals but were different in their sociodemographic profiles. Finally, "anti-vaccine" and other "vaccine hesitant" individuals were in class $3(42.21 \%)$.

Conclusions This study showed the vaccine characteristics that are likely to improve vaccine uptake, which may more easily lead to herd immunity. Different profiles of respondents also showed various levels of acceptance toward a COVID-19 vaccination program, which may help to better understand vaccine hesitancy behaviors.
\end{abstract}

\section{Introduction}

As of 24 November, 2021, 5,166,192 deaths had been reported due to the novel coronavirus disease 2019 (COVID-19) [1]. Following the race to develop a vaccine, four vaccines are now available in Canada [2] (PfizerBioNTech, Moderna, Janssen, and AstraZeneca), 25 have been granted emergency use authorizations by national authorities, and seven have been approved by the World

Thomas G. Poder

thomas.poder@umontreal.ca

1 Department of Management, Evaluation and Health Policy, School of Public Health, University of Montreal, 7101 Parc Avenue, Montreal, QC H3N 1X9, Canada

2 Centre de recherche de l'Institut universitaire en santé mentale de Montréal, CIUSSS de l'Est de l'île de Montréal, 7331 rue Hochelaga, Montreal, QC H1N 3V2, Canada

3 Centre interuniversitaire de recherche en analyse des organisations, 1130 Rue Sherbrooke O \#1400, Montreal, QC H3A 2M8, Canada

\section{Key Points for Decision Makers}

This is the first study to conduct a discrete choice experiment to elicit preferences of the Quebec population toward a vaccination program.

Beyond effectiveness and side effects, the duration of the protective effect and the origin of the vaccine were found to be the most preferred attributes.

This study provided indications that vaccination hesitancy is likely not a dichotomic issue with "pro-vaccine" and "anti-vaccine". 
Health Organization (WHO)-recognized stringent regulatory authority. Each of these vaccines has specific characteristics in terms of efficacy (from 62 to $95 \%$ ), side effects (e.g., pain, redness, fever, swelling), number of doses (one or two shots), or technology used (viral vector or messenger RNA). Regarding the side effects, several safety concerns have appeared. Blood clots were observed following the vaccines from AstraZeneca, which was restricted to adults aged under 55 years in Canada in late March 2021 [3], and from Johnson \& Johnson in the USA, which was not recommended for women aged under 50 years in April 2021 [4]. Additionally, vaccine hesitation and aversion in some groups can be explained by health controversies and scandals, such as Dengvaxia [5] or the Pandemrix [6-8], and by false information/misinformation, such as associations with autism $[9,10]$ or multiple sclerosis [11], the use of aluminum [12], or new technologies such as messenger RNA [13, 14].

The growing hesitation of populations about vaccination is a major issue in the COVID-19 crisis. As defined by MacDonald and the SAGE Working Group on Vaccine Hesitancy, "vaccine hesitancy refers to delay in acceptance or refusal of vaccination despite availability of vaccination services. Vaccine hesitancy is complex and context specific, varying across time, place and vaccines. It is influenced by factors such as complacency, convenience and confidence" [15]. To achieve herd immunity, it is necessary to understand which populations are hesitant to better meet their demands and thus increase the uptake of a vaccine.

Using a discrete choice experiment (DCE), we aimed to assess the vaccination preferences of the Quebec population and to establish sociodemographic profiles to highlight which characteristics of the vaccination program are of particular importance in the decision to receive the vaccine. Our DCE is the first conducted in Canada to achieve this aim. Although information on COVID-19 vaccine preferences remains fragmented and limited to a few countries, some vaccine attributes are recurrent in the recent literature (e.g., effectiveness, safety, protection duration).

For instance, in China, Leng et al. [16] estimated that a vaccine with $85 \%$ effectiveness and a low probability of side effects is strongly preferred, while other attributes were considered of lower importance. According to the best vaccine scenario, they estimated an $85 \%$ uptake. Dong et al. [17] found similar preferences in addition to a protection duration of 18 months or more. Among healthcare workers, Fu et al. [18] found that those attributes were not always as important as in studies that targeted a general representative population. Indeed, these authors underlined the importance of the perceived trend of the epidemic and the infection probability over effectiveness.
In Europe, McPhedran and Toombs [19] showed a high utility induced by a vaccine effectiveness of $90 \%$ compared with a level of $70 \%$ in the British population. In France, the study by Schwarzinger et al. [20] highlighted the importance of the origin of the vaccine. Indeed, the general French adult population preferred a vaccine manufactured in the European Union or in the USA and rejected a Chinese vaccine, showing a preference for Western countries. They also found a consistent decrement in preferences about the effectiveness and the risk of serious side effects.

In the USA, Kreps et al. [21] and Motta [22] found similar results with a preference for the USA as the manufacturer compared to the UK, China, or Russia, and a consistent decrement in preferences for the effectiveness and the probability of side effects of the vaccine. Kreps et al. also added the recommender of the vaccine as an important attribute in vaccine choice and found a preference for a vaccine recommended by the Centers for Disease Control and Prevention or by the WHO. Craig [23] estimated an $86 \%$ probability of uptake under the best vaccine scenario (i.e., effective and safe) with a choice of setting and vaccination card offered. He highlighted that anti-vaccine proponents tended to be less educated and less vulnerable to severe forms of COVID-19 illness (e.g., younger adults, without medical conditions).

In Australia, Borriello et al. [24] estimated the probability of uptake at $99 \%$ in the best-case scenario. However, in this study, effectiveness was not considered as important as safety, and individuals also gave importance to the date until when the vaccine was available.

Other DCEs related to the COVID-19 vaccination program have been conducted but aimed to assess the preference for deservingness and priority populations. Luyten et al. [25] defined two prioritization strategies for a vaccination program based on five attributes, including belonging to a medical risk group, being a virus spreader, and being an essential worker. They defined a "utilitarian" strategy consisting of prioritizing spreaders of the virus and a "prioritarian" strategy consisting of prioritizing the medical risk groups. Another study by Reeskens et al. [26] defined a profile of an individual who should get prioritized for vaccination: an individual aged between 40 and 60 years, in a healthy condition, who respects the COVID-19 measures and is a healthcare worker. In the Netherlands, priority preference was given to young and health-worker individuals with high risk-conscious behavior [27].

In this study, which was conducted prior to the start of the vaccine program, we focused mainly on the origin, effectiveness, and safety of the vaccine, as well as on who recommended the vaccine and which groups should be given priority. In the next sections, we describe the methodology used and then present and discuss the results. 


\section{Methodology}

\subsection{Survey Design}

Our target population was the French-speaking Quebec population aged over 18 years. The online survey was conducted between 19 October and 17 November, 2020 by Dynata Inc. and was structured to achieve quota sampling by age, sex, and educational level with reference to the national statistics provided by the Institut de la Statistique du Québec. The sampling was done among the panel owned by Dynata Inc. To reach a statistical power of $95 \%$ with a first-species risk $\alpha$ of 3\% (i.e., rejecting the null hypothesis when it is actually true) and a relevant population of 6.5 million, 1067 individuals were needed (https://fr.surveymonkey.com/mp/ sample-size-calculator/). Consequently, this was the minimal sample size targeted to have a representative sample of the French-speaking general population in Quebec. In addition, some authors have suggested a minimum of 10-20 responses per choice task $[28,29]$. Considering that we had 360 choice tasks (see below) and that each respondent answered 12 choice tasks, this suggestion was achieved with a minimum of 600 respondents (i.e., $360 * 20 / 12$ ).

The survey included a sociodemographic section, questions related to health condition, COVID-19 experience, the Fear of COVID19 Scale (FCV-19S) [30], health-related quality-of-life questionnaires [31-33], the DCE with followup questions, personal vaccination perception questionnaire, and the 3-item Sense of Coherence questionnaire (SOC-3) [34]. The sociodemographic section included age, sex, marital status, household income, occupation, education, type of residence, and family information. The FCV-19S is a 7-item validated questionnaire with a 5-point Likert scale range from "strongly disagree" to "strongly agree". The higher the score, the higher the fear of COVID-19. We measured vaccination trust via four questions whose sum scored between 0 and 5 (the higher the score, the higher the vaccination trust). We also measured vaccination hesitancy via an eightitem questionnaire with a five-point Likert scale inspired by Shapiro et al. [35] and calculated a score range from 0 to 32 (the higher the score, the higher the vaccination aversion). Both latter questionnaires are partially validated instruments as they were adapted from previous questionnaires for child immunization acceptance. In this study, they were mainly used to summarize the information about trust and hesitancy.

\subsection{DCE Design, Attribute, and Levels}

As recommended by various experts in the field [36-38], we performed a mixed-methods study to build our DCE questionnaire. First, we conducted a rapid review of the literature to find relevant information about the attributes and levels of vaccination programs that are of importance for people in their decision to be vaccinated or not. This was done in PubMed and Scopus using the keywords "discrete choice experiment" and "vaccine". This led to various studies [17, 39-45], including reviews of the literature and original studies dealing with focus groups and published surveys. A first list of attributes and levels that can be used to influence vaccine choice was set at this stage. Second, we consulted experts in public health $(n=2)$ and health economics $(n=$ $1)$, as well as a few citizens $(n=3)$, to hear their opinion about what was found in the literature and to provide insight into other potential attributes. This was done face to face through a phone or web meeting. This information made it possible to determine the attributes and levels to be used to characterize the risks and benefits of the vaccine and thus to define choice tasks for the DCE. In particular, this led to a list of eight attributes that were considered important, and one was excluded because it would have generated incoherent choice tasks combined with the other attributes (i.e., number of injections). The levels for each attribute were then adjusted to the extant knowledge about future vaccines that will be available by the end of 2020 as well as political concerns in Quebec (e.g., which population to prioritize, acceptable delay). Some levels were also selected for their capacity to ensure a better discrimination (i.e., effectiveness, side effects, protective duration). The experts and citizens then considered through an iterative process by e-mails whether the attributes and levels used made sense and qualitatively validated the questionnaire. This was done with a specific focus on univocity (i.e., unambiguous) of the phrasing and relevance of the attributes and levels based on the judgment of the participants. Likewise, a pretest was carried out on individuals from the general population to validate the consistency and unambiguity of the content of the questionnaire.

Our DCE was composed of seven attributes with three to six levels each (Table 1). Using an orthogonal selection procedure, a set of 300 choice tasks was produced. Each choice task consisted of two scenarios, and an opt-out option (no vaccine) was allowed. These choice tasks were randomly divided into 30 blocks. In each block, a rationality test was added (i.e., one scenario completely dominated the other scenario), and one choice task was repeated (choice tasks 2 and 12) to test the temporal consistency of respondents. This yielded a total of 360 choice tasks. Each respondent was randomly attributed one block of choice tasks. An illustration of a choice task is presented in Fig. 1. The first column in the choice task corresponded to the generic names of the seven attributes, the second to the levels presented in vaccine program $\mathrm{A}$, and the third to the levels presented in vaccine program $B$. In the database, each possible choice (i.e., A, B, or opt-out) for each choice task corresponded to an observation (i.e., yielding three observations [or a triad] per choice task responded). Dummies were created for each 
level of the seven attributes, and each dummy was coded with a value of 1 when the level was described in the vaccination program offered and 0 otherwise [46]. In the estimates, levels were dummy coded relative to the best level of each attribute. For the alternative specific constant, which captures the experimentally designed profiles in the survey, if the respondent answered choice A or B, the first two observations in each triad were coded 1 , and the third observation for the opt-out option was coded 0 ; if the respondent answered the opt-out choice, the first two observations in each triad were coded 0 , and the third observation for the opt-out option was coded 1.

\subsection{Models}

Two models were tested: a mixed-logit (MXL) model [47, 48] and a latent class logit (LCL) model [49, 50]. The MXL model estimates the distribution of the mean and the standard deviation of each individual's preferences. The LCL model allows the generation of different groups of individuals presenting similar preference patterns (intra-class) that are heterogeneous from one group to another (inter-class). For the sake of clarity, the models are presented with the best vaccination program as a reference: a vaccine manufactured in Canada, 95\% efficacy with the fewest side effects, 24 months of protection duration, elderly individuals as a priority population, a waiting time of 2 months, and both the WHO and the Quebec Public Health Department as recommenders. Models were assessed using Akaike Information Criteria and likelihood function. The LCL model was run with several classes, and we based our choice on the Akaike Information Criteria, the likelihood function, and the interpretation of the results.

\subsection{Descriptive Analysis}

Using the LCL model, descriptive analyses were performed with five classes as well as with the full sample. We presented each class and the full sample with its sociodemographic characteristics and all relevant information aforementioned. We also computed several scores: certainty of DCE choices, FCV-19S, vaccination trust, vaccine hesitancy, and SOC-3. We used means to describe continuous variables. Finally, depending on the nature of the variable, we tested independence between classes using the Chi-squared test, Fisher's exact test, or Kruskal-Wallis test and means' test equality with analysis of variance. A $p$ value less than 0.1 was considered statistically significant. Because these results do not consider confounding effects, a multinomial logistic regression to measure the class membership probability function was also conducted and used respondent characteristics as arguments.

\subsection{Ethics}

This study was approved by the ethics committee of our institution. Subjects indicated their consent by clicking on the start button at the end of the explanatory letter. All questionnaires were completed anonymously.

\section{Results}

\subsection{Sample}

Of the 3615 individuals solicited to participate, 1980 accepted, and 1696 completed the DCE. Among these 1696 , several were excluded because they responded to the 12 choice tasks in the DCE in less than 1 minute and chose the opt-out option $75 \%$ of the time or less ( $n$ $=47 ; 2.77 \%)$, they always responded choice $\mathrm{A}(n=15$; $0.88 \%)$ or choice $\mathrm{B}(n=2 ; 0.12 \%)$, they responded that their answers were of "poor" or "very poor" quality ( $n$ $=8 ; 0.47 \%$ ), or they indicated not having answered their best $(n=42 ; 2.48 \%)$. This led to 97 individuals dropping out $(5.72 \%)$ and to a full sample of 1599 individuals for analysis.

The answers for analysis corresponded to 19,188 choices, including 14,072 (73.34\%) vaccine choices and 5116 vaccine refusals (26.66\%). Approximately $37.71 \%$ of the sample never chose the opt-out option, $7.44 \%$ always chose to not get vaccinated, $11.44 \%$ refused the vaccine in the first-choice task (i.e., rationality test), $3.50 \%$ chose the second scenario (i.e., choice B was dominated by choice A), and $74.23 \%$ made the same choice to both scenarios 2 and 12 (i.e., consistency test). The refusal rate was $28.05 \%$ over choice tasks $2-12$.

\subsection{Choice Models}

The main results of the MXL model are presented in Table 2, and the coefficients were ordered as expected when relevant (a version without the alternative specific constant is presented in the Electronic Supplementary Material [ESM]). All parameters were significant at least at $p<0.1$, except for the levels "mild fevers" and " 4 months". On average, there was a preference for Western countries (Canada, European Union, and USA) as vaccine producers; Russia and China led to a strong disutility. A vaccine effectiveness of $85 \%$ showed a negative marginal utility compared to a $95 \%$ effectiveness, thus indicating that a vaccine may be unlikely to be accepted at $85 \%$ and below. A one-third chance of having side effects, such as redness, mild itching, or mild fever, did not appear to matter. However, a one-third chance of being 
Table 1 Discrete choice experiment attributes and levels

\begin{tabular}{|c|c|}
\hline Attributes & Levels \\
\hline Vaccine origin & $\begin{array}{l}\text { Canada } \\
\text { USA } \\
\text { European Union } \\
\text { Russia } \\
\text { China } \\
\text { Japan }\end{array}$ \\
\hline Vaccine effectiveness (\%) & $\begin{array}{l}95 \\
85 \\
60 \\
30\end{array}$ \\
\hline Side effects of the vaccine & $\begin{array}{l}1 \text { in } 3 \text { chances of having redness and mild itching at the injection site for } 1 \text { or } 2 \text { days } \\
1 \text { in } 3 \text { chances of having mild fevers for } 1 \text { or } 2 \text { days } \\
1 \text { in } 3 \text { chances of being hospitalized in an intensive care unit for } 10 \text { days }\end{array}$ \\
\hline Duration of vaccine protection (months) & $\begin{array}{l}3 \\
9 \\
24\end{array}$ \\
\hline Priority population to receive the vaccine & $\begin{array}{l}\text { No priority population } \\
\text { Healthcare workers will be prioritized as soon as the vaccine becomes available } \\
65 \text { years and over will be prioritized as soon as the vaccine becomes available }\end{array}$ \\
\hline $\begin{array}{l}\text { Waiting time to get vaccinated when a vaccine will be } \\
\text { available (months) }\end{array}$ & $\begin{array}{l}2 \\
4 \\
8\end{array}$ \\
\hline Recommender of the vaccine & $\begin{array}{l}\text { World Health Organization } \\
\text { Quebec Public Health Department } \\
\text { World Health Organization and Quebec Public Health Department }\end{array}$ \\
\hline
\end{tabular}

hospitalized following vaccination was very likely to lead to vaccine refusal. A duration of protection of at least 9 months was well accepted, while a period of 3 months resulted in greater disutility. Regarding the priority population, our sample was indifferent, with a very slight preference to prioritize the older population. Notably, this attribute had the lowest relative weight. Individuals were indifferent to a waiting time period to get vaccinated of 4 months compared to 2 months, whereas a waiting time of 8 months resulted in a significant but quite low disutility compared with the magnitudes of other coefficients. Finally, both the recommendations of the WHO and of the Quebec Public Health Department were necessary to best meet the expectations of our sample. If this was not the case, the recommendation of the Quebec Public Health Department was preferred to that of the WHO. The preference ranking between attributes is presented in Table 3 and was as follows: effectiveness, safety, duration, origin, recommendation, waiting time, and priority population.

Considering that preferences are generally heterogeneous, we ran a LCL model that resulted in five classes. We predicted the posterior class membership probabilities [48] and considered the maximum probability to assign individuals to each class. We first present the vaccine preferences and then describe the five classes with all characteristics and scores presented above. Note that coefficient estimates are also presented graphically in the ESM for both models.

\subsection{Preference Analysis by Classes}

The results of the LCL are presented in Table 4, and the relative weights of the attributes are presented in Table 3. An analysis with four classes is also provided in the ESM. Class 1 (share of 0.117 ) had very few significant coefficients. Mainly, the delay to get vaccinated and the recommender of the vaccine had an impact on individuals' utilities. In class 2 (share of 0.097), almost all levels were associated with strong disutility compared with the reference. Individuals preferred a vaccine that can cause moderate fevers instead of redness/itching but especially not hospitalization, 95\% efficacy, with as short a delay to get vaccinated as possible, and of Canadian origin. Individuals in class 3 (share of 0.308 ) granted a high disutility if the vaccine was not 


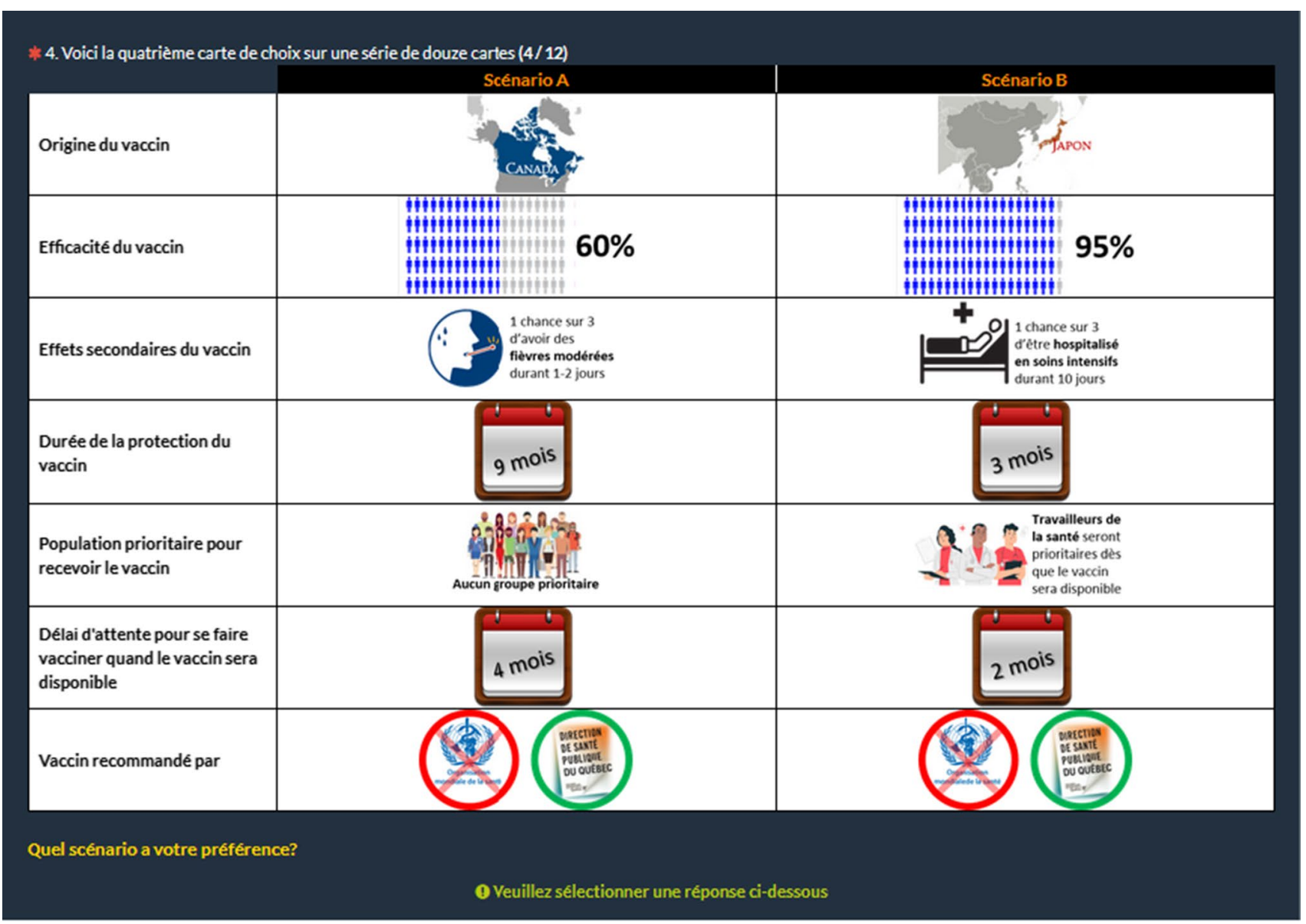

- Scénario A

Scénario $B$

Aucun de ces scénarios (pas de vaccin)

Fig. 1 A vaccine choice card illustration (in French)

at least at $85 \%$ effective, with moderate side effects, and a minimal protective duration of 9 months. Class 4 preferences (share of 0.195) were identical to those of class 2 but very less pronounced. Finally, class 5 (share of 0.283 ) individuals wanted a vaccine with a Western country origin, at least $85 \%$ effective, with moderate fevers as side effects and a minimal protective duration of 9 months. Except for class 2, individuals did not take into account the priority population or the delay to get vaccinated in their choice tasks.

\subsection{Descriptive Analysis by Classes}

The following descriptive facts are given for informational purposes and to highlight the fact that there is no single behavior in vaccine choice, which reflects both the importance of the vaccination program characteristics and those of the respondents (Table 5 and ESM). Half of the respondents were women (male/female ratio of 0.95$)[p=$ $0.018]$ and the sample had a mean age of 50.23 years $(p<$ 0.001 ) [ESM]. Classes 2 and 4 were mainly composed of men (male/female ratios equal to 1.16 and 1.26 , respectively), and class 3 was mainly feminine (male/female ratio equal to 0.78). Class 1 was the youngest (45.62) and class 4 the oldest (53.64). Most participants were married/lived with a partner $(59.10 \%)$ or single $(28.77 \%)[p=0.001]$ and were employed $(51.09 \%)$ or retired $(32.27 \%)$ [ $p=0.040]$. Individuals in class 1 were more employed $(59.59 \%)$ and students $(6.16 \%)$, and individuals in classes 2 and 4 were mainly retired $39.02 \%$ and $37.55 \%$, respectively) and married or living with a partner $(64.23 \%$ and $62.45 \%$, respectively). One-third were poorly educated $(p=0.064)$, with classes 1 and 4 being the least educated $(42.47 \%$ and $40.71 \%$, respectively, had the lowest educational level) and class 2 being the most educated $(41.46 \%$ had the highest 


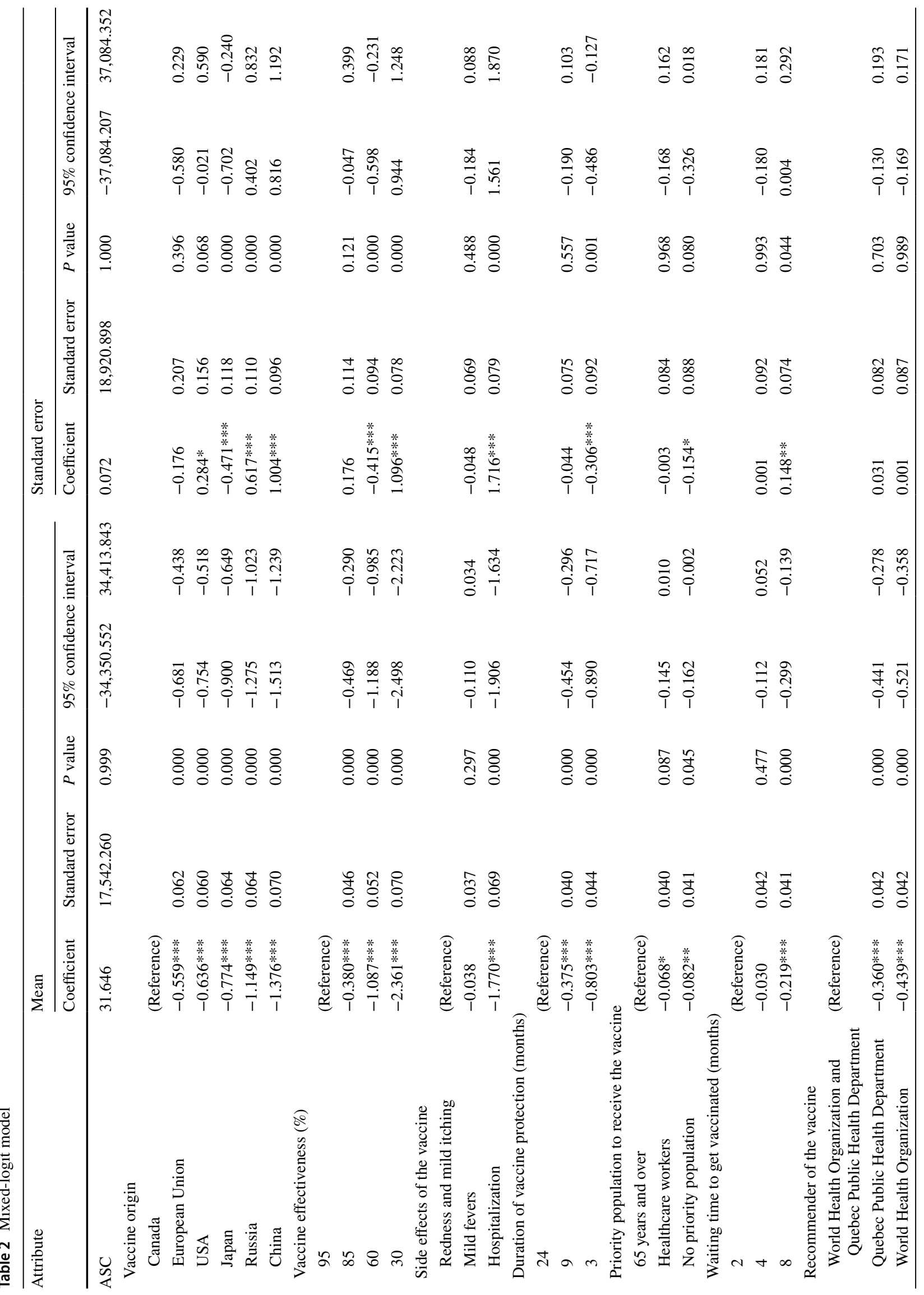






educational level). The average household annual income ranged from $63,356 \mathrm{CAD}$ in class 1 to $77,134 \mathrm{CAD}$ in class 2 , with a mean of $66,857 \mathrm{CAD}(p<0.001)$. The sample was thus somewhat representative of the adult Quebec population (ESM). Other data showed that half of the sample did not experience financial losses due to COVID-19 ( $p=0.143)$ and continued to work during the first lockdown $(p=0.430)$. Class 3 suffered the least from financial losses $(52.15 \%)$, while class 1 suffered the most from financial losses (21.43\% declared "fairly significant" or "very significant" financial losses) and continued to work $(56.16 \%)$. Only $10.82 \%$ declared their health status as "fair" or "poor" $(p=0.303)$, with a maximum in class 2 $(13.01 \%)$. The willingness to take risks was equal to 4.69 of $10(p<0.001)$. Individuals in classes 1 and 5 were the most risk lovers (5.47 and 5.00, respectively). Almost 30\% declared suffering from a disease or a clinical or mental health problem $(p=0.112)$. The health-related quality-oflife scores were lower only in class 1 (ESM).

The average response time to the DCE was 5 minutes 8 seconds ( $p=0.045$ ), with class 4 being the fastest (4 minutes) and class 3 being the slowest (5 minutes 35 seconds) [ESM]. The choice certainty score was equal to 95.61 of $120(p<0.001)$, with a minimum in class 1 (84.32) and a maximum in class 3 (98.52). Class 2 was more likely to declare the exercise as "easy" or "very easy" $(65.85 \%, p$ $=0.011)$, to consider at least three dimensions $(71.54 \%, p$ $<0.001)$, and to declare a "good" or "very good" quality of answers $(94.31 \%, p<0.001)$. This was in contrast to classes 1 and 4 . More than $40 \%$ of choices in class 3 were vaccine refusals $(p<0.001)$, while it was approximately $15 \%$ in classes 1,2 , and 5 compared with $26.66 \%$ in the total sample.

Vaccine trust and vaccine hesitancy scores were equal to 4.08 of $5(p<0.001)$ [i.e., high trust] and 11.61 of $32(p$ $<0.001$ ) [i.e., moderate hesitancy], respectively (Table 5). Classes 1 and 3 had the lowest vaccine trust score and the highest vaccine hesitancy score (3.83 and 14.03 in class 1 and 3.75 and 12.22 in class 3, respectively), while class 2 was the most confident (4.48) and the least hesitant (9.72). Regarding COVID-19, the FCV-19S was equal to 16.45 of $35(p<0.001)$, with a maximum in class $1(18.45)$. About $1.81 \%$ of individuals caught the virus $(p=0.010)$, while this proportion was $4.01 \%$ for a family member ( $p$ $=0.015)$ and $10.76 \%$ for a relative $(p=0.077)$. Individuals in class 1 were the most likely to declare having suffered from the disease, while in class 4 , they were the least likely. Last, the SOC-3 was approximately 3.94 of 6 $(p=0.078)$ with a minimum in class 1 (3.67) [ESM]. The results of the multinomial logistic regression confirmed that many of the variables presented above explained the probability of belonging to the 5 classes identified (ESM). 
Table 3 Relative weights of attributes according to the different models

\begin{tabular}{llrrrrr}
\hline & $\begin{array}{l}\text { Mixed- } \\
\text { logit } \\
\text { model }\end{array}$ & \multicolumn{6}{l}{ Latent class logit model } \\
\cline { 5 - 7 } & & Class 1 & Class 2 & Class 3 & Class 4 & Class 5 \\
\hline Relative weights of attributes by model (\%) & 12.75 & 5.06 & 11.57 & 5.78 & 35.93 & 9.84 \\
Vaccine origin & 28.48 & 15.56 & 19.50 & 20.80 & 15.93 & 48.61 \\
Effectiveness of the vaccine & 23.68 & 12.98 & 33.99 & 35.74 & 8.64 & 9.09 \\
Side effects of the vaccine & 17.41 & 4.46 & 3.67 & 18.35 & 11.71 & 24.43 \\
Duration of vaccine protection & 2.11 & 9.80 & 7.99 & 1.72 & 1.18 & 0.73 \\
Priority population to receive the vaccine & 3.62 & 24.03 & 16.33 & 3.16 & 4.14 & 2.68 \\
Waiting time to get vaccinated & 11.96 & 28.12 & 6.95 & 14.45 & 22.48 & 4.62 \\
Recommender of the vaccine & & & & & & \\
\hline
\end{tabular}

\section{Discussion}

In this study, we assessed the vaccination preferences against COVID-19 in the Quebec population. Using a DCE, we showed the relevance of the effectiveness, safety, and protective duration of the vaccine in the choice of vaccination of individuals. As preferences may vary depending on groups' characteristics [51], we also analyzed the heterogeneity of behaviors with an LCL model. Five profiles emerged from our analysis: an average group in favor of vaccines (class 5); two vaccine hesitant and very demanding groups (classes 2 and 4); a very hesitant group with many anti-vaccine individuals (class 3 ); and an uncertain, impatient, more vulnerable group or those who did not understand the DCE and may have provided inconsistent answers (class 1). Indeed, the latter is composed of individuals who wanted to be vaccinated as soon as possible and were more exposed to the disease. Classes 2 and 4 were very demanding regarding different attributes. However, class 2 granted a higher relative weight to vaccine effectiveness and side effects. Class 4 was mainly worried about the vaccine origin and who recommends it. Both attributes can be summarized as a form of trust in Western institutions. All respondents who always refused the vaccine $(7.44 \%)$ were in class 3 (some descriptive facts are available in the ESM), and we can suppose that they were "anti-vaccine". However, most respondents in class 3 were "vaccine hesitant" individuals $(17.63 \%$ of the class always refused the vaccine program, $60.89 \%$ chose to accept the vaccine program at least once, and $21.48 \%$ always accepted the vaccine program) and granted the highest utility to vaccine safety. Class 5 can be considered a "pro-vaccine" group that gave a very high importance to effectiveness and protective duration. This class had few discriminant characteristics, and the majority of sociodemographic variables, DCE-related variables, and COVID-19 experience variables were equal to those of the full sample. In brief, if the available vaccines are efficient, manufactured in Western countries and with low side effects; classes 2 and 4 should decide to get vaccinated.

As in other studies, we found that vaccine acceptance tends to increase with age, education, and income [52-58]. It has been shown that female individuals were more hesitant to get vaccinated against COVID-19 $[17,56,59,60]$ or were willing to wait longer [61], which is also in line with our findings: the largest proportion of women were in the group of hesitant and anti-vaccine individuals (class 3). Elderly patients seemed to be more concerned about side effects and were more demanding regarding vaccine characteristics (classes 2 and 4). A higher fear of COVID-19 and vaccine trust also increased the willingness to get vaccinated [60, 62], whereas individuals with current health problems and who had an experience with COVID-19 were less likely to accept the vaccine [51, 62].

Our results match different opinion polls conducted in Canada. According to an IPSOS survey for Radio Canada [63] conducted in December 2020, 63\% of residents were willing to get vaccinated, and $72 \%$ were worried about vaccination side effects. In March 2021 [64], 66\% were willing to get vaccinated, and $16 \%$ preferred to wait. Long-term side effects were the main reason to refuse the vaccine.

In Canada, COVID-19 vaccines are available for free. Thus, we did not consider the price as an attribute as it could have been misperceived. Some studies have included the vaccine price as an attribute, but it was associated with low coefficients or was not significant $[16,17,24]$.

Our survey suffers from several limitations. The first is linked to the fact that an online survey may create a selection bias. Individuals who did not have access to the Internet or had poor literacy were thus excluded. However, $93 \%$ of adult residents have access to the Internet in Quebec [65], which may have limited this bias. In addition, an online survey also allowed us to better manage social desirability bias [66] and to treat the information faster, in addition to being less expensive. Another constraint of an online survey is related to the financial incentive offered by the platform to the respondents, which could have fostered them to adopt 
Table 4 Latent class logit model with five classes

\begin{tabular}{|c|c|c|c|c|c|}
\hline Attribute & Class 1 & Class 2 & Class 3 & Class 4 & Class 5 \\
\hline \multicolumn{6}{|l|}{ Latent class logit mdoel } \\
\hline ASC & 81.735 & 124.144 & 48.588 & 48.221 & 46.778 \\
\hline \multicolumn{6}{|l|}{ Vaccine origin } \\
\hline Canada & (Reference) & & & & \\
\hline European Union & -0.105 & $-10.233 * * *$ & $-0.434 * *$ & $-1.007 * * *$ & $-0.660 * * *$ \\
\hline USA & -0.093 & $-6.369 * * *$ & $-0.738 * * *$ & $-0.995 * * *$ & $-0.678 * * *$ \\
\hline Japan & -0.053 & $-13.377 * * *$ & $-0.510^{* * *}$ & $-1.697 * * *$ & $-0.700 * * *$ \\
\hline Russia & -0.048 & $-16.034 * * *$ & $-0.731 * * *$ & $-2.697 * * *$ & $-0.883^{* * *}$ \\
\hline China & 0.090 & $-18.225^{* * *}$ & $-1.017 * * *$ & $-3.478 * * *$ & $-0.810 * * *$ \\
\hline \multicolumn{6}{|l|}{ Vaccine effectiveness (\%) } \\
\hline 95 & (Reference) & & & & \\
\hline 85 & 0.030 & $-7.679 * * *$ & $-0.370 * *$ & -0.109 & $-0.721 * * *$ \\
\hline 60 & -0.204 & $-9.292 * * *$ & $-1.143 * * *$ & $-0.455^{* * *}$ & $-1.996 * * *$ \\
\hline 30 & -0.214 & $-23.843 * * *$ & $-3.126^{* * *}$ & $-1.121 * * *$ & $-4.191 * * *$ \\
\hline \multicolumn{6}{|l|}{ Side effects of the vaccine } \\
\hline Redness and mild itching & (Reference) & & & & \\
\hline Mild fevers & 0.004 & $0.657 * *$ & $-0.200 *$ & -0.096 & 0.055 \\
\hline Hospitalization & $-0.204 *$ & $-40.397 * * *$ & $-4.315 * * *$ & $-0.417 * * *$ & $-0.671 * * *$ \\
\hline \multicolumn{6}{|l|}{ Duration of vaccine protection (months) } \\
\hline 24 & (Reference) & & & & \\
\hline 9 & 0.047 & $-0.314 * *$ & $-0.614 * * *$ & -0.168 & $-0.546 * * *$ \\
\hline 3 & 0.016 & $-3.558 * * *$ & $-1.454 * * *$ & $-0.456 * * *$ & $-1.211 * * *$ \\
\hline \multicolumn{6}{|c|}{ Priority population to receive the vaccine } \\
\hline 65 years and over & (Reference) & & & & \\
\hline Healthcare workers & -0.004 & $-5.035 * * *$ & 0.085 & 0.005 & -0.008 \\
\hline No priority population & -0.133 & $-4.047 * * *$ & $-0.119^{*}$ & 0.057 & -0.045 \\
\hline \multicolumn{6}{|l|}{ Waiting time to get vaccinated (months) } \\
\hline 2 & (Reference) & & & & \\
\hline 4 & -0.095 & $-10.415^{* * *}$ & $0.274 *$ & 0.045 & -0.069 \\
\hline 8 & $-0.257 * *$ & $-8.200 * * *$ & $-0.115^{*}$ & -0.182 & -0.132 \\
\hline \multicolumn{6}{|l|}{ Recommender of the vaccine } \\
\hline $\begin{array}{l}\text { World Health Organization and } \\
\text { Quebec Public Health Depart- } \\
\text { ment }\end{array}$ & (Reference) & & & & \\
\hline Quebec Public Health Department & -0.087 & $-4.785 * * *$ & $-0.709 * * *$ & $-0.599 * * *$ & $-0.160 *$ \\
\hline World Health Organization & $-0.305^{* * *}$ & $-2.505 * * *$ & $-0.898 * * *$ & $-0.581 * * *$ & $-0.168 *$ \\
\hline Class share & 0.117 & 0.097 & 0.308 & 0.195 & 0.283 \\
\hline Observations & 1599 & & & & \\
\hline LLF & -6020.47 & & & & \\
\hline AIC & $12,238.95$ & & & & \\
\hline
\end{tabular}

AIC Akaike Information Criterion, ASC alternative specific constant, $L L F$ likelihood function, $* p<0.1$; $* * p<0.05 ; * * * p<0.01$

"satisficer" behavior and to answer with weak coherence in a relatively short time $[67,68]$. This could explain the results of class 1 despite the use of exclusion criteria.

A second limitation is related to the design of the DCE. Indeed, we chose seven attributes, which may have led to a cognitive burden for respondents. There is still debate about the optimal number of attributes in the literature [69-71], but increasing the number of attributes increases the likelihood of self-simplifying the exercise by heuristics [72]. Several preference-based surveys about COVID-19 vaccination included six [17, 22, 27] or seven [16, 18, 21, 24] attributes.

Third, the study was designed before the first COVID19 vaccines were available. Although it was based on the best knowledge at that time, it could have led to a hypothetical bias by choosing attributes that were not of utmost importance in the actual (real) situation. In addition, by 
Table 5 Coronavirus disease 2019 (COVID-19) experiences and vaccine hesitancy

\begin{tabular}{|c|c|c|c|c|c|c|c|}
\hline $\begin{array}{l}\text { COVID-19 and vac- } \\
\text { cine hesitancy }\end{array}$ & Class 1 & Class 2 & Class 3 & Class 4 & Class 5 & Total & $P$ value \\
\hline \multicolumn{8}{|c|}{ Vaccine trust score (range from 0 to 5$)^{\mathrm{a}}$} \\
\hline Mean & 3.83 & 4.48 & 3.75 & 4.30 & 4.46 & 4.08 & \multirow[t]{2}{*}{$<0.001$} \\
\hline Standard deviation & 1.42 & 0.88 & 1.66 & 1.08 & 0.95 & 1.39 & \\
\hline \multicolumn{8}{|c|}{ Vaccine hesitancy score (range from 0 to 32$)^{b}$} \\
\hline Mean & 14.03 & 9.72 & 12.22 & 10.88 & 10.75 & 11.61 & \multirow[t]{2}{*}{$<0.001$} \\
\hline Standard deviation & 5.99 & 5.75 & 7.09 & 6.12 & 6.08 & 6.59 & \\
\hline \multicolumn{8}{|c|}{ Fear of COVID-19 score (range from 7 to 35$)^{c}$} \\
\hline Mean & 18.45 & 16.32 & 15.17 & 17.49 & 17.27 & 16.45 & \multirow[t]{2}{*}{$<0.001$} \\
\hline Standard deviation & 6.84 & 5.58 & 5.67 & 6.62 & 6.34 & 6.22 & \\
\hline \multicolumn{8}{|c|}{ Have you or a relative been sick with COVID-19 in the past few months? } \\
\hline \multicolumn{8}{|l|}{ Yourself } \\
\hline Yes & $6.16 \%$ & $1.63 \%$ & $1.48 \%$ & $0.79 \%$ & $1.49 \%$ & $1.81 \%$ & \multirow[t]{2}{*}{0.010} \\
\hline No & $93.84 \%$ & $98.37 \%$ & $98.52 \%$ & $99.21 \%$ & $98.51 \%$ & $98.19 \%$ & \\
\hline \multicolumn{8}{|l|}{ A family member } \\
\hline Yes & $8.90 \%$ & $5.69 \%$ & $3.11 \%$ & $2.77 \%$ & $4.23 \%$ & $4.07 \%$ & \multirow[t]{2}{*}{0.015} \\
\hline No & $91.10 \%$ & $94.31 \%$ & $96.89 \%$ & $97.23 \%$ & $95.77 \%$ & $95.93 \%$ & \\
\hline \multicolumn{8}{|l|}{ A relative } \\
\hline Yes & $17.12 \%$ & $11.38 \%$ & $10.52 \%$ & $7.91 \%$ & $10.45 \%$ & $10.76 \%$ & \multirow[t]{2}{*}{0.077} \\
\hline No & $82.88 \%$ & $88.62 \%$ & $89.48 \%$ & $92.09 \%$ & $89.55 \%$ & $89.24 \%$ & \\
\hline
\end{tabular}

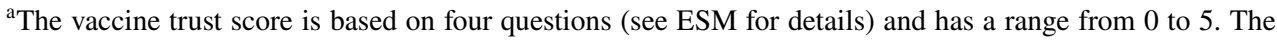
"Yes/No" questions are encoded 1 and 0 and the fourth question is encoded 0,1 , and 2 . The score corresponds to the sum of each modality

${ }^{\mathrm{b}}$ The vaccine hesitancy score is based on eight questions (see ESM for details) with a 5-point Likert scale from "Strongly disagree" ( 0 or 4$)$ to "Strongly agree" (4 or 0$)$. The modality "Do not know" is encoded 2 and questions $3,4,5$, and 7 have been reversed. The score per individual corresponds to the sum of each modality

${ }^{c}$ The fear of COVID-19 score is based on the 7-item Fear of COVID-19 scale (see ESM for details) with a 5-point Likert scale from "Strongly disagree" (1) to "Strongly agree" (5). The score has a range from 7 to 35 and corresponds to the sum of each modality considering the most appropriate and realistic levels for these attributes, it allowed us to limit the potential dependency between some attributes, such as the priority population and the waiting time to get vaccinated. However, scientific information about the disease and vaccines, their availability, and public trust are rapidly evolving, and this study needs to be considered within its context at the time it was conducted. Future studies should examine vaccine programs as the situation evolves (e.g., variants, long-term COVID-19) by considering other attributes. Moreover, we did not use a simple question to ask respondents if they were willing to get vaccinated against COVID-19 when the vaccine was available. Instead, we performed a DCE and assessed their general behavior when facing vaccination with additional questions.

One of the strengths of the study is that the sample size was quite large (1599 individuals) [73] compared to the average sample size of other DCEs about the COVID-19 vaccination program in the literature. It was also above the minimal requirement, thus ensuring higher efficiency in estimates. Finally, both the MXL and the LCL models were consistent in their results and in the decrement in disutility according to effectiveness, probability of side effects, protection duration, and waiting time to get vaccinated.

In 2019, the WHO classified vaccine hesitancy as one of the top ten threats to global health [74]. Nevertheless, it does not rely on a dichotomic view with "anti-vaccine" on the one hand and "pro-vaccine" on the other hand but on a continuum between those two extremes. Hesitancy to vaccination is multifactorial. Determinants explaining vaccination hesitancy and refusal are contextual (influences and media), individual (sociodemographic, knowledge, and experiences), and organizational (availability, healthcare worker perception, and vaccine characteristics) [75]. We believe that this study reflects this situation well, although it was more about vaccine choice than hesitancy per se. Indeed, the LCL model clearly indicated five main groups with diverse behaviors regarding whether they chose to accept a vaccine, and this choice was potentially driven both by the characteristics of the vaccination program and their own sociodemographic and attitudinal characteristics. 


\section{Conclusions}

Vaccination campaigns should consider various attributes of the program as well as individual profiles to improve trust in vaccination programs and expand herd immunity. However, this requires transparent and consistent information [76]. Different behaviors regarding vaccination restrict global immunization (i.e., vaccine hesitancy and vaccine refusal) and are worse during the COVID-19 crisis. The comprehension of such behaviors is crucial in determining the success of a vaccination campaign. In this study, we examined the preferences of the general population in Quebec and highlighted several characteristics of vaccine behavior patterns that should help decision makers establish a more effective vaccination campaign.

Supplementary Information The online version contains supplementary material available at https://doi.org/10.1007/s40273-021-01124-4.

Acknowledgements We thank all experts and participants who participated in the design and the completion of the survey. Both authors contributed equally to the design, analysis, and writing of this study. TGP is member of the FRQS-funded Centre de recherche de l'IUSMM.

\section{Declarations}

Funding This study was funded through a research fund of the Fondation de l'Institut Universitaire en Santé Mentale de Montréal (IUSMM) and benefitted from the assistance of the Centre Interuniversitaire de Recherche en Analyse des Organisations (CIRANO).

Conflict of interest The authors have no conflicts of interest to declare.

Ethics Approval This study was approved by the Ethics Committee of the CIUSSS de l'Est de l'île de Montréal under the number 2021-2385.

Consent to participate Informed consent was obtained from participants before to start the survey.

Consent for publication All authors provide this consent.

Availability of Data and Material Because of restrictions from our ethics committee, data will be available upon reasonable request by contacting the corresponding author.

Code availability Please contact the corresponding author for any requests for any study materials including codes.

Open Access This article is licensed under a Creative Commons Attribution-NonCommercial 4.0 International License, which permits any non-commercial use, sharing, adaptation, distribution and reproduction in any medium or format, as long as you give appropriate credit to the original author(s) and the source, provide a link to the Creative Commons licence, and indicate if changes were made. The images or other third party material in this article are included in the article's Creative Commons licence, unless indicated otherwise in a credit line to the material. If material is not included in the article's Creative Commons licence and your intended use is not permitted by statutory regulation or exceeds the permitted use, you will need to obtain permission directly from the copyright holder. To view a copy of this licence, visit http://creativecommons.org/licenses/by-nc/4.0/.

\section{References}

1. World Health Organization. WHO coronavirus (COVID-19) dashboard. Available from: https://covid19.who.int. [Accessed $24 \mathrm{Nov}$ 2021].

2. Government of Canada. Vaccines for COVID-19. 16 December 2020. Available from: https://www.canada.ca/en/public-health/ services/diseases/coronavirus-disease-covid-19/vaccines.html. [Accessed 23 Nov 2021].

3. CNN. Canada halting AstraZeneca vaccine shots for people 55 and younger. https://www.cnn.com/2021/03/29/americas/canada-astra zeneca-vaccine-intl/index.html. Accessed 30 Apr 2021.

4. Centers for Disease Control and Prevention. COVID-19 vaccination. 11 February 2020. https://www.cdc.gov/coronavirus/2019ncov/vaccines/safety/JJUpdate.html. Accessed 3 Aug 2021.

5. Fatima K, Syed NI. Dengvaxia controversy: impact on vaccine hesitancy. J Glob Health. 2018;82:010312. https://doi.org/10. 7189/jogh.08-020312 (PMID: 30410732).

6. Nihlén FJ. Vaccine hesitancy and trust. Ethical aspects of risk communication. Scand J Public Health. 2017;462:182-8. https:// doi.org/10.1177/1403494817727162 (PMID: 28847220).

7. Weibel D, Sturkenboom M, Black S, et al. Narcolepsy and adjuvanted pandemic influenza A (H1N1) 2009 vaccines: multi-country assessment. Vaccine. 2018;3641:6202-11. https://doi.org/10. 1016/j.vaccine.2018.08.008 (PMID: 30122647).

8. Centers for Disease Control and Prevention. Vaccine safety. Narcolepsy following 2009 Pandemrix influenza vaccination in Europe. 20 Aug 2020. https://www.cdc.gov/vaccinesafety/conce rns/history/narcolepsy-flu.html. Accessed 30 Apr 2021.

9. Taylor LE, Swerdfeger AL, Eslick GD. Vaccines are not associated with autism: an evidence-based meta-analysis of case-control and cohort studies. Vaccine. 2014;17(3229):3623-9. https://doi. org/10.1016/j.vaccine.2014.04.085.

10. Centers for Disease Control and Prevention. Vaccine safety. Autism and vaccines. 2021 Jan 26. https://www.cdc.gov/vacci nesafety/concerns/autism.html. Accessed 30 Apr 2021.

11. World Health Organization. The Global Advisory Committee on Vaccine Safety rejects association between Hepatitis B vaccination and multiple sclerosis (MS). https://www.who.int/vaccine_ safety/committee/topics/hepatitisb/ms/en/. Accessed 30 Apr 2021.

12. Goullé J-P, Grangeot-Keros L. Aluminum and vaccines: current state of knowledge. Med Mal Infect. 2020;501:16-21. https://doi. org/10.1016/j.medmal.2019.09.012 (PMID: 31611133).

13. Chirumbolo S. Vaccination hesitancy and the "myth" on mRNAbased vaccines in Italy in the COVID-19 era: does urgency meet major safety criteria? J Med Virol. 2021. https://doi.org/10.1002/ jmv.26922 (PMID: 33666240).

14. Centers for Disease Control and Prevention. Understanding mRNA COVID-19 vaccines. 4 Mar 2021. www.cdc.gov/coronavirus/2019-ncov/vaccines/different-vaccines/mrna.html. Accessed 30 Apr 2021.

15. MacDonald NE, SAGE Working Group on Vaccine Hesitancy Vaccine hesitancy: definition, scope and determinants. Vaccine. 2015;3334:4161-4. https://doi.org/10.1016/j.vaccine.2015.04. 036. PMID: 25896383

16. Leng A, Maitland E, Wang S, Nicholas S, Liu R, Wang J. Individual preferences for COVID-19 vaccination in China. Vaccine. 2021;392:247-54. https://doi.org/10.1016/j.vaccine.2020.12.009 (PMID: 33328140).

17. Dong D, Xu RH, Wong ELY, et al. Public preference for COVID19 vaccines in China: a discrete choice experiment. Health Expect. 
2020;236:1543-78. https://doi.org/10.1111/hex.13140 (PMID: 33022806).

18. Fu C, Wei Z, Pei S, Li S, Sun X, Liu P. Acceptance and preference for COVID-19 vaccination in health-care workers (HCWs). MedRxiv. 2020. https://doi.org/10.1101/2020.04.09.20060103.

19. McPhedran R, Toombs B. Efficacy or delivery? An online discrete choice experiment to explore preferences for COVID-19 vaccines in the UK. Econ Lett. 2021;200:109747. https://doi.org/10.1016/j. econlet.2021.109747 (PMID: 33551522).

20. Schwarzinger M, Watson V, Arwidson P, Alla F, Luchini S. COVID-19 vaccine hesitancy in a representative working-age population in France: a survey experiment based on vaccine characteristics. Lancet Public Health. 2021. https://doi.org/10.1016/ S2468-2667(21)00012-8 (PMID: 33556325)

21. Kreps S, Prasad S, Brownstein JS, et al. Factors associated with US adults' likelihood of accepting COVID-19 vaccination. JAMA Netw Open. 2020;310:2025594. https://doi.org/10.1001/jaman etworkopen.2020.25594 (PMID:33079199).

22. Motta M. Can a COVID-19 vaccine live up to Americans' expectations? A conjoint analysis of how vaccine characteristics influence vaccination intentions. Soc Sci Med. 2021;1(272):113642. https://doi.org/10.1016/j.socscimed.2020.113642.

23. Craig BM. United States COVID-19 vaccination preferences (CVP): 2020 hindsight. Patient. 2021. https://doi.org/10.1007/ s40271-021-00508-0. PMID: 33783724

24. Borriello A, Master D, Pellegrini A, Rose JM. Preferences for a COVID-19 vaccine in Australia. Vaccine. 2020;393:473-9. https:// doi.org/10.1016/j.vaccine.2020.12.032 (PMID: 33358265).

25. Luyten J, Tubeuf S, Kessels R. Who should get it first? Public preferences for distributing a COVID-19 vaccine. Covid Economics, Vetted and Real-Time Papers. 2020;57.

26. Reeskens T, Roosma F, Wanders E. The perceived deservingness of COVID-19 healthcare in the Netherlands: a conjoint experiment on priority access to intensive care and vaccination. BMC Public Health. 2021;211:447. https://doi.org/10.1186/ s12889-021-10488-3.

27. MG, Ie K, Se S, Jl T, Cgm G-O, Ja van T. Public preferences in priority setting when admitting patients to the ICU during the COVID-19 crisis: a pilot study. Patient. 2021. https://doi.org/10. 1007/s40271-021-00504-4. PMID: 33748930

28. Lancsar E, Louviere J. Conducting discrete choice experiments to inform healthcare decision making: a user's guide. Pharmacoeconomics. 2008;268:661-77. https://doi.org/10.2165/00019 053-200826080-00004. PMID: 18620460

29. Burgess L, Street DJ, Wasi N. Comparing designs for choice experiments: a case study. J Stat Theory Pract. 2011;1(51):25-46. https://doi.org/10.1080/15598608.2011.10412048.

30. Ahorsu DK, Lin C-Y, Imani V, Saffari M, Griffiths MD, Pakpour $\mathrm{AH}$. The fear of COVID-19 scale: development and initial validation. Int J Ment Health Addict. 2020;27:1-9. https://doi.org/10. 1007/s11469-020-00270-8 (PMID: 32226353).

31. Mulhern BJ, Bansback N, Norman R, Brazier J, S-6Dv2 International Project Group. Valuing the SF-6Dv2 classification system in the United Kingdom using a discrete-choice experiment with duration. Med Care. 2020;586:566-73. https://doi.org/10.1097/ MLR.0000000000001324.

32. Xie F, Pullenayegum E, Gaebel K, et al. A time trade-off-derived value set of the EQ-5D-5L for Canada. Med Care. 2016;541:98105. https://doi.org/10.1097/MLR.0000000000000447.

33. Mavranezouli I, Brazier JE, Rowen D, Barkham M. Estimating a preference-based index from the Clinical Outcomes in Routine Evaluation-Outcome Measure (CORE-OM): valuation of CORE6D. Med Decis Making. 2013;1(333):381-95. https://doi.org/10. 1177/0272989X12464431.

34. Schumann A, Hapke U, Meyer C, Rumpf H-J, John U. Measuring sense of coherence with only three items: a useful tool for population surveys. Br J Health Psychol. 2003;8(Pt 4):40921. https://doi.org/10.1348/135910703770238275 (PMID: 14614789).

35. Shapiro GK, Tatar O, Dube E, et al. The vaccine hesitancy scale: psychometric properties and validation. Vaccine. 2018;365:660 7. https://doi.org/10.1016/j.vaccine.2017.12.043 (PMID: 29289384).

36. Louviere JJ, Lancsar E. Choice experiments in health: the good, the bad, the ugly and toward a brighter future. Health Econ Policy Law. 2009;4(Pt 4):527-46. https://doi.org/10.1017/S174413310 9990193 (PMID: 19715635).

37. Coast J, Al-Janabi H, Sutton EJ, et al. Using qualitative methods for attribute development for discrete choice experiments: issues and recommendations. Health Econ. 2012;216:730-41. https:// doi.org/10.1002/hec. 1739 .

38. Bridges JFP, Hauber AB, Marshall D, et al. Conjoint analysis applications in health: a checklist: a report of the ISPOR Good Research Practices for Conjoint Analysis Task Force. Value Health. 2011;144:403-13. https://doi.org/10.1016/j.jval.2010. 11.013 (PMID: 21669364).

39. de Bekker-Grob EW, Veldwijk J, Jonker M, et al. The impact of vaccination and patient characteristics on influenza vaccination uptake of elderly people: a discrete choice experiment. Vaccine. 2018;3611:1467-76. https://doi.org/10.1016/j.vaccine.2018.01. 054 (PMID: 29426662).

40. Dubé E, Gagnon D, Ouakki M, et al. Understanding vaccine hesitancy in Canada: results of a consultation study by the Canadian Immunization Research Network. PLoS ONE. 2016;116:e0156118. https://doi.org/10.1371/journal.pone. 0156118 (PMID: 27257809).

41. MacDonald NE, Butler R, Dubé E. Addressing barriers to vaccine acceptance: an overview. Hum Vaccin Immunother. 2017;141:218-24. https://doi.org/10.1080/21645515.2017. 1394533 (PMID: 29048975).

42. Kestenbaum LA, Feemster KA. Identifying and addressing vaccine hesitancy. Pediatr Ann. 2015;444:71-5. https://doi.org/10. 3928/00904481-20150410-07 (PMID: 25875982).

43. Nagata JM, Hernández-Ramos I, Kurup AS, Albrecht D, VivasTorrealba C, Franco-Paredes C. Social determinants of health and seasonal influenza vaccination in adults $\geq 65$ years: a systematic review of qualitative and quantitative data. BMC Public Health. 2013;13:388. https://doi.org/10.1186/1471-2458-13-388 (PMID: 23617788).

44. Eilers R, Krabbe PFM, de Melker HE. Factors affecting the uptake of vaccination by the elderly in Western society. Prev Med. 2014;69:224-34. https://doi.org/10.1016/j.ypmed.2014. 10.017 (PMID: 25456809).

45. Liao Q, Ng TWY, Cowling BJ. What influenza vaccination programmes are preferred by healthcare personnel? A discrete choice experiment. Vaccine. 2020;3829:4557-63. https://doi. org/10.1016/j.vaccine.2020.05.012 (PMID: 32414654).

46. McFadden D. Conditional logit analysis of qualitative choice behavior. In: Zarembka P, editor. Frontiers in econometrics. New York (NY): Academic Press; 1973. p. 105-42.

47. Hole AR. Fitting mixed logit models by using maximum simulated likelihood. Stata J. 2007;1(73):388-401. https://doi.org/ 10.1177/1536867X0700700306.

48. Hole AR. Mixed logit modelling in Stata: an overview.

49. Pacifico D, Yoo H. Lclogit: a Stata command for fitting latentclass conditional logit models via the expectation-maximization algorithm. Stata J. 2013;1(133):625-39. https://doi.org/10.1177/ $1536867 X 1301300312$.

50. Yoo HI. lclogit2: an enhanced command to fit latent class conditional logit models. Stata J. 2020;1(202):405-25. https://doi. org/10.1177/1536867X20931003. 
51. Grüner S, Krüger F. The intention to be vaccinated against COVID-19: stated preferences before vaccines were available. Appl Econ Lett. 2020;30:1-5. https://doi.org/10.1080/13504 851.2020 .1854445$.

52. Lin Y, Hu Z, Zhao Q, Alias H, Danaee M, Wong LP. Understanding COVID-19 vaccine demand and hesitancy: a nationwide online survey in China. PLoS Negl Trop Dis. 2020 Dec;1412:e0008961. PMID: 33332359. doi: https://doi.org/10. 1371/journal.pntd.0008961.

53. Malik AA, McFadden SM, Elharake J, Omer SB. Determinants of COVID-19 vaccine acceptance in the US. EClinicalMedicine. 2020. https://doi.org/10.1016/j.eclinm.2020.100495 (PMID: 32838242).

54. Shekhar R, Sheikh AB, Upadhyay S, et al. COVID-19 vaccine acceptance among health care workers in the United States. Vaccines (Basel). 2021. https://doi.org/10.3390/vaccines90 20119 (PMID: 33546165).

55. Lazarus JV, Ratzan SC, Palayew A, et al. A global survey of potential acceptance of a COVID-19 vaccine. Nat Med. 2021;272:225-8. https://doi.org/10.1038/s41591-020-1124-9 (PMID: 33082575)

56. Murphy J, Vallières F, Bentall RP, et al. Psychological characteristics associated with COVID-19 vaccine hesitancy and resistance in Ireland and the United Kingdom. Nat Commun. 2021;4(121):29. https://doi.org/10.1038/s41467-020-20226-9.

57. Kourlaba G, Kourkouni E, Maistreli S, et al. Willingness of Greek general population to get a COVID-19 vaccine. Glob Health Res Policy. 2021;61:3. https://doi.org/10.1186/s41256-021-00188-1 (PMID: 33509291)

58. Kelly BJ, Southwell BG, McCormack LA, et al. Predictors of willingness to get a COVID-19 vaccine in the U.S. BMC Infect Dis. 2021;211:338. https://doi.org/10.1186/s12879-021-06023-9.

59. Robertson E, Reeve KS, Niedzwiedz CL, et al. Predictors of COVID-19 vaccine hesitancy in the UK household longitudinal study. Brain Behav Immun. 2021. https://doi.org/10.1016/j.bbi. 2021.03.008 (PMID: 33713824).

60. Detoc M, Bruel S, Frappe P, Tardy B, Botelho-Nevers E, Gagneux-Brunon A. Intention to participate in a COVID-19 vaccine clinical trial and to get vaccinated against COVID-19 in France during the pandemic. Vaccine. 2020;3845:7002-6. https://doi.org/ 10.1016/j.vaccine.2020.09.041 (PMID: 32988688).

61. Tervonen T, Jimenez-Moreno AC, Krucien N, Gelhorn H, Marsh K, Heidenreich S. Willingness to wait for a vaccine against COVID-19: results of a preference survey. Patient. 2021;14(3):373-7. https://doi.org/10.1007/s40271-020-00483-y.

62. Szmyd B, Karuga FF, Bartoszek A, et al. Attitude and behaviors towards SARS-CoV-2 vaccination among healthcare workers: a cross-sectional study from Poland. Vaccines. 2021;93:218. https:// doi.org/10.3390/vaccines9030218.

63. Radio Canada. COVID-19: les deux tiers des Canadiens veulent se faire vacciner. https://ici.radio-canada.ca/nouvelle/1753508/coron avirus-vaccin-sondage-ipsos-doutes-effets-secondaires-attente. Accessed 19 Apr 2021

64. Angus Reid Institute. COVID-19: Canadians' willingness to be inoculated right away increases again as new vaccine approved. 8 March 2021. https://angusreid.org/covid-vaccine-march/. Accessed 19 Apr 2021.

65. Le Soleil. $93 \%$ des adultes québécois possèdent une connexion Internet à la maison. 31 July 2019. https://www.lesoleil.com/affai res/93-des-adultes-quebecois-possedent-une-connexion-interneta-la-maison-2a1b83f5cd7e69712fd885c968b55045. Accessed 27 Apr 2021.

66. Koivula A, Räsänen P, Sarpila O. Examining social desirability bias in online and offline surveys. In: Kurosu M, editor. Humancomputer interaction. Perspectives on design. Cham: Springer International Publishing; 2019. p. 145-58.

67. Malhotra N. Completion time and response order effects in web surveys. Public Opin Q. 2008;1(725):914-34. https://doi.org/10. 1093/poq/nfn050.

68. Barge $\mathrm{S}$, Gehlbach $\mathrm{H}$. Using the theory of satisficing to evaluate the quality of survey data. Res High Educ. 2012;1(532):182-200. https://doi.org/10.1007/s11162-011-9251-2.

69. Mühlbacher A, Johnson FR. Choice experiments to quantify preferences for health and healthcare: state of the practice. Appl Health Econ Health Policy. 2016;143:253-66. https://doi.org/10. 1007/s40258-016-0232-7 (PMID: 26992386).

70. Ryan M, Gerard K. Using discrete choice experiments to value health care programmes: current practice and future research reflections. Appl Health Econ Health Policy. 2003;21:55-64 (PMID: 14619274).

71. Louviere JJ, Pihlens D, Carson R. Design of discrete choice experiments: a discussion of issues that matter in future applied research. J Choice Modelling. 2011;1(41):1-8. https://doi.org/10. 1016/S1755-5345(13)70016-2.

72. Burton M, Rigby D. The self selection of complexity in choice experiments. Am J Agr Econ. 2012;943:786-800. https://doi.org/ 10.1093/ajae/aas015.

73. Reed Johnson F, Lancsar E, Marshall D, et al. Constructing experimental designs for discrete-choice experiments: report of the ISPOR Conjoint Analysis Experimental Design Good Research Practices Task Force. Value Health. 2013;1(161):3-13. https:// doi.org/10.1016/j.jval.2012.08.2223.

74. WHO. Ten threats to global health in 2019. https://www.who. int/news-room/spotlight/ten-threats-to-global-health-in-2019. Accessed 20 Apr 2021.

75. Dubé E, Vivion M, MacDonald NE. Vaccine hesitancy, vaccine refusal and the anti-vaccine movement: influence, impact and implications. Expert Rev Vacc. 2015;141:99-117. https://doi.org/ 10.1586/14760584.2015.964212 (PMID: 25373435).

76. Craxì L, Casuccio A, Amodio E, Restivo V. Who should get COVID-19 vaccine first? A survey to evaluate hospital workers' opinion. Vaccines (Basel). 2021. https://doi.org/10.3390/vacci nes9030189 (PMID: 33668695). 